\title{
The Design of the Contents of an e-Learning for Teaching M.5 English Language Using ADDIE Model
}

\author{
H. Wiphasith, R. Narumol, and C. Sumalee
}

\begin{abstract}
Nowadays, teaching and learning English use electronic learning (e-learning) as an alternative for presentation and contents delivery. These e-learning materials are effective tools to attract the attention of the participants and to capture the students' interest. The students can access contents anytime, anywhere, and according to their cognitive abilities. However, for the e-learning processes to be effective in facilitating the students' learning processes, it is necessary to have steps and procedures in contents design and development based on Instructional System Design (ISD). In order for teaching and learning processes to be successful, the students must learn from the appropriately designed contents. Therefore, this research aims to propose the principles and processes in contents design of an e-learning tool for M.5 (Grade 11) English subject using the ADDIE model. This model consists of the following steps: analysis, design, development, implementation, and evaluation. The contents were developed and then evaluated by five content experts. The result showed that most experts accepted the designed and development contents. After this, the researchers will use these contents to investigate these M.5 students' learning outcomes from cooperative learning with STAD technique - a comparison between normal virtual classrooms and virtual classrooms with scaffolding.
\end{abstract}

Index Terms-Contents design, ADDIE model, English subject.

\section{INTRODUCTION}

English is the first foreign language which the Ministry of education of Thailand introduced into the curriculum of primary and secondary school, and public and private schools [1], [2] for 12 years. However, the problems of English teaching among Thai children from the past to the present were not addressed according to expectations [3]. Comparisons between the ability to use the language of the learners and the time to be wasted on teaching [4] were made. These are shown by the results of the English test scores of the M.6 students in the Ordinary National Educational Test (O-NET) for the last four years. The average percentage of the scores were $19.22,21.80,22.13$ and 25.35 respectively [5]. The information above shows that in average, Thai students have scores lower than 50 percent. Such problem arises from both the instructors and the students. Specific

Manuscript received August 5, 2014; revised October 10, 2014. This work was supported in part by the Suranaree University of Technology, Thailand and Rajamangala University of Technology Isan, Surin Campus, Thailand.

H. Wiphasith and R. Narumol are with the School of Information Technology, Social Technology, Suranaree University of Technology, Thailand (e-mail: wiphasith@hotmail.com, narumol.n@sut.ac.th).

C. Sumalee is with the Education Technology, Faculty of Education, Khon Kaen University, Thailand (e-mail: sumalee@kku.ac.th). problems of the students include them having basic and insufficient knowledge of English, impatience, and lack of confidence in using the language. They also lack motivation, enthusiasm and dislike English. Also, they think that English is not the national language. These problems make the students uninterested in learning [3], [6], [7]. In addition, it also found that the primary factor that impedes the learning and teaching of English is restricted mostly to the classroom [8]. As a result of these problems, learners cannot use English to communicate and researching of knowledge from many sources in the information age to obtain effective [9]. Therefore, the stakeholders should help to solve these problems so that the students are enthusiastic to learn and can use English effectively in the criteria. Learning and teaching English should not be limited in the classroom. Teachers should have a creative system and learning environment that would train the students and allow them to use different languages [10].

Nowadays, the advancement of information technology has influenced changes in teaching and learning through the instructional materials which are not limited to the classroom. Electronic learning (e-learning) is an innovative type of education technology that is appropriate to adopt in teaching primary to higher levels of education. They are using the Computer Mediated Communication (CMC) [11] which is a two-way communication learning which the students and instructors are separated by distance. The e-learning has a process similar to normal classroom teaching. Learners and instructors can communicate via the web-board and the chat-room. At the same time, the students can learn with their satisfaction, anytime, anywhere, and according to their cognitive abilities [12]. The e-learning is a tool used to create knowledge, access to information, and inequality in education in order to promote changes in the society in the future.

Recently, e-learning used in the teaching of English courses- supplementary, complementary, and comprehensive roles, which based on the form of synchronous and asynchronous [13], depending on the content's purposes of the each lesson. The e-learning helps raise the quality of education and optimize teaching and learning as it can be a tool for transferring the knowledge to the students, accessing information and as a medium of communication. The causes that these e-learning materials offers various multimedia tools such as images, animation, video, and audio. In addition, it has been delivering content that looks similar to the real environment or a regular classroom.

However, students' learning should not become dependent on the e-learning's presentation features such text, graphics, sound, animation and video or links to information sources around the world, but these should be used in design process 
of teaching and learning materials which are designed to be delivered to the learners [14].

The principle of Instructional System Design (ISD) is a systematic process for planning the teaching system. The objective is to help the students learn in a systematic way and can be measured by the ability of learners to learn from the truth [15]. Educators have invented the many principles of Instructional Model (IM) such as ADDIE Model, Dick and Carey Model, Gerlach and Ely Model, Knirk and Gustafson Model, Jerrold Kemp Model, and Hannafin and Peck Model, etc. [15], [16], and applied these to the design of e-learning materials.

The ADDIE model is an instructional model which is a popular and generally- accepted model can be used in the design and development of e-learning as well [15], [16]. It consists of five stages: analysis, design, development, implementation, and evaluation. Each stage is a flexible approach used to create a tool effectively. However, for e-learning and for helping the students achieve learning objectives, one of the key elements is content because students will spend the most time studying on their own. There are a variety of activities that focus on the challenge [13]. Therefore, the contents design, quiz and test design of each subject in e-learning are essential that must principle of content design, to guide in to convey and presentation of content to the learners systematically.

The learning of an English subject in e-learning is mainly about individual learning wherein students must learn, practice and think on their own, to modify the contents which instructor prepared for them and store these as knowledge and to enable the students to change their behavior according to the aim of the learning activity. Then, e-learning is necessary to undergo proper design of contents based on the instructional system design principle. This article presents the design contents of an e-Leaning tool for M.5 English subject that uses the ADDIE model.

\section{LITERATURE REVIEW}

\section{A. Introduction to Contents}

Contents are information which are of the essence, and are to be used for additional experiences of knowledge and skills to learners. They are tools for creating knowledge and understanding the story.

In teaching, contents are identified as the "subject matter" because they are the focus of the lesson which contains many subjects in the course. Contents are directly correlated with the behavioral objectives. These objectives will determine the information to be presented to students. The concepts identified are according to learner and learning needs. This is often called the concept, so the contents, concepts and objectives are a relationship [15].

The English subject for M.5 consists of 16 chapters that include Home from home, Where in the world, Testing times, Modern romance, Looking good, Nice work, Food for thought, Going places, Life experiences, Shopaholics, Tourist attractions. , That's entertainment, Dreams, The best days of your life, Tomorrow's world and Dilemmas [17]. All chapters are divided into 2 parts: chapters 1 to 8 for the first semester and chapters 9 to 16 for the second semester.

\section{B. ADDIE Model}

The ADDIE model is process of instructional system design and was developed by B. Seel and Z. Glasgow, This model takes the initial letter from each of the five components: Analysis, Design, Development, Implementation and Evaluation. Each of the step is presented below: [16].

1) Analysis (A): This phase is the first step in ADDIE model. It is the process of defining what is to be learned and has 3 steps: Needs analysis, Task analysis and Instructional analysis.

2) Design (D): This phase is a process which leads to the goals and is driven by a search for the answers to the following questions: "What instructional strategy will achieve the objectives?", "What are the objectives?", "How will we know if the objectives are met?"

3) Development (D): The process of authoring and producing the materials by the implementation or development of media according to the result of analysis. The questions are as follows: "What will the materials say?", "How will the materials look and sound?", "Do students meet quality standards?", "Do students learn from the media?" and "How do we improve media?"

4) Implement (I): It is the process of installing media and using media among the target audience.

5) Evaluation (E): This phase is the process of determining the impact of the instruction and evaluating the media used in bringing outcomes in order to improve the quality of this media.

\section{Methodology}

The research methodologies of the ADDIE model which this paper have two steps are as follows:

\section{A. Analysis: (A)}

The researchers have studied the problems of teaching English in Thailand. The teaching in the normal classroom and teaching using electronic media were studied. After that, researchers collected papers about learning and teaching English for upper secondary school from content experts. The details are as follows:

1) Needs Analysis: The researchers analyzed the current problems of teaching English in Thailand. Results show that teaching English in Thailand are facing problems and crises. It can be seen through the scores of the Ordinary National Educational Test (O-NET) which are in the lower zone. Results show that learning English is boring and nowadays, education in Thailand has focused on developing individual competitiveness. In addition, the preparation of the learning sources has no clear direction. These problems affect the student's achievement. In particular, students of the upper secondary level need to be prepared for competition in the entrance exam or applying for jobs.

2) Learner Analysis: In the instructional analysis phase, in order to develop the good quality and appropriateness of the tool and the course, the researchers analyzed the 
learners' basic knowledge of English by inquiring and collecting data from the English teacher at the upper secondary school. The result showed that the students have a basic knowledge and ability learning in the English is different level. They're appearing from the students' grades in semester ago. It also found that each student have interests and learning differences. From the analysis of the above, students may be divided into 3 levels according to grade (excellent, medium and poor level)

3) Task Analysis: This process is about bringing the English book which is Elevator 2 for M. 5 (second semester) [17] to cluster analysis, task inventory, sequencing, and task knowledge. The steps of this process are as follows:

- Cluster Analysis: For identifying and clustering of sub-tasks in a coral pattern. Included are the identified task, subtask and sub sub-task. This will be useful for measuring the learning of the students as they are measured in all tasks. (For example see Fig. 1 - Fig. 3)

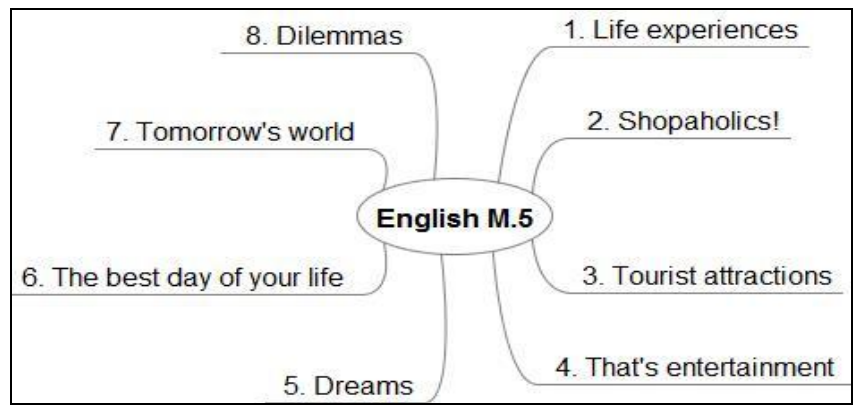

Fig. 1. Example of the contents ' analysis of tasks.

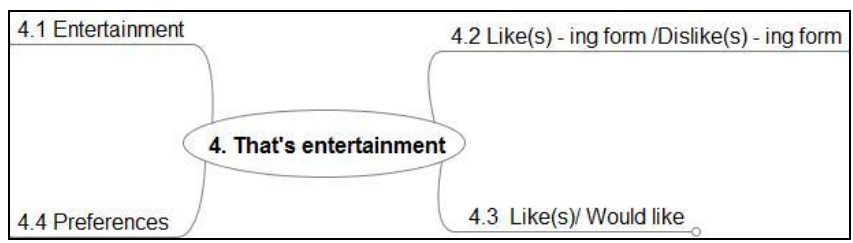

Fig. 2. Example of the contents ' analysis of 4. That's entertainment subtask.

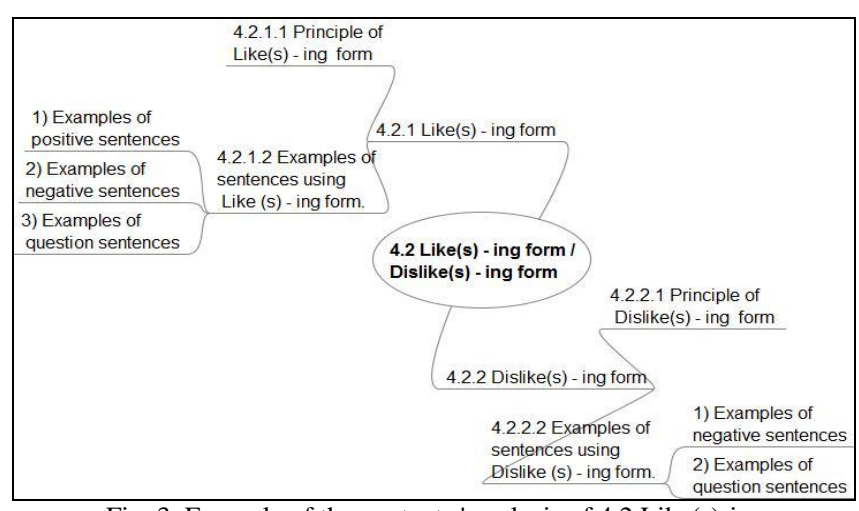

Fig. 3. Example of the contents ' analysis of 4.2 Like(s)-ing form/Dislike(s)-ing form sub sub-task on subtask 4. That's entertainment.

- Task Inventory: This phase involves coming up with the topics of tasks which have analyzed the contents. The topic of tasks were written in groups and the content is divided into tasks and sub-tasks. (see Fig. 4).

- Sequencing: The hierarchical relationships of task are to sequence content that is presented in the lesson. After that, the relationship of the tasks is shown in network diagrams.

- Task knowledge: It involves the specification of each task's subtasks which the learners need to know. It is divided into 2 categories: Specific Task Knowledge and General Task Knowledge (see Fig. 5).

\begin{tabular}{||l|c||}
\hline Subtask & Sub-subtask \\
\hline 4. That's & 4.2Like(s) - ing form / Dislike(s) - ing form \\
entertain- & 4.2.1 Like(s) - ing form \\
ment & 4.2.1.1 Principle of Like(s) -ing form \\
& 4.2.1.2 Examples of sentences using Like(s) - \\
& ing form \\
& 1) Examples of positive sentences \\
& 2) Examples of negative sentences \\
& 3) Examples of question sentences \\
\hline
\end{tabular}

Fig. 4. The design of topic 4.2 Like(s)-ing form/ Dislike(s)-ing form on subtask 4 . That's entertainment.

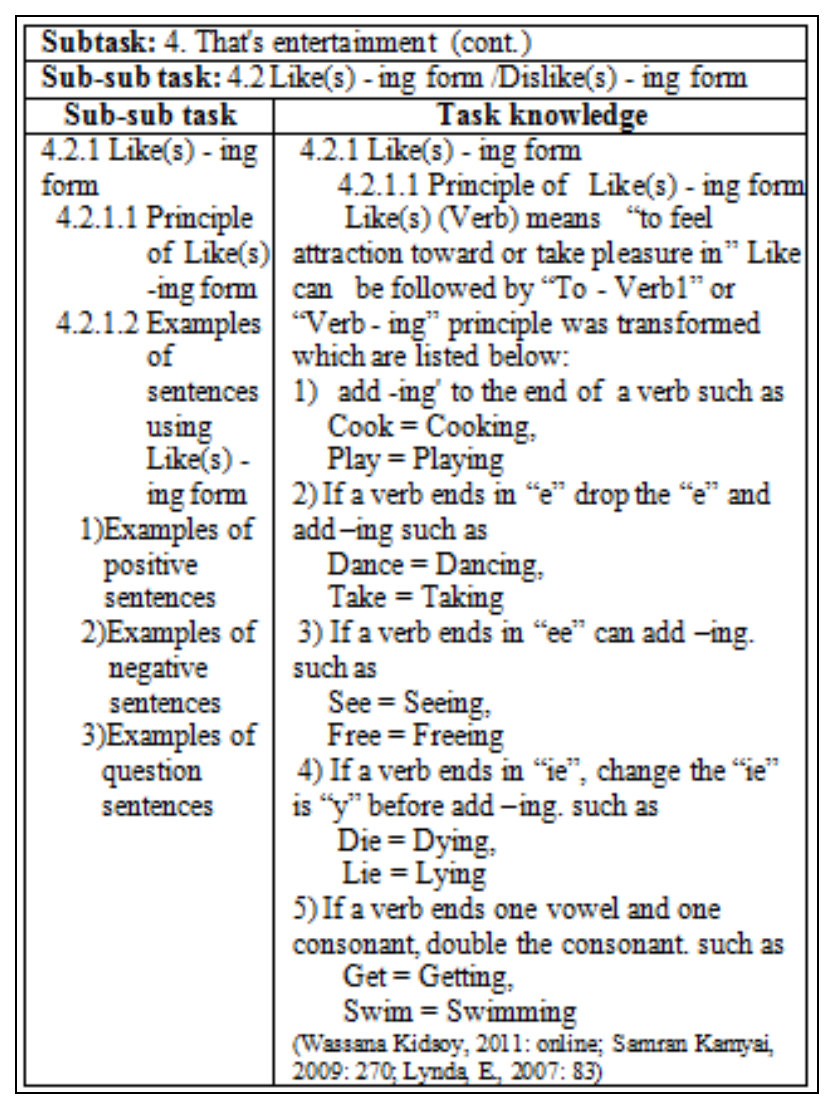

Fig. 5. Analysis of the sub-subtask 4.2 Like(s)-ing form/ Dislike(s)-ing form on subtask 4. That's entertainment.

\section{B. Design: (D)}

This phase involves designing the different objectives of learning and testing, which includes the following steps:

1) Objectives design: The steps for objectives design are as follows:

- Input / Action / Output Diagram: To enable the students can see the task of practice and practice's outcome (see Fig. 6). In addition, defined observable and measurable learning outcome (see Fig. 7).

- Defining behavioral learning objectives: This involves presenting the topics of the task from the analysis of the design of the behavioral learning objectives in an ABCD format (see Fig. 8). 


\begin{tabular}{||l|l|l||}
\hline Subtask: & \multicolumn{2}{|c|}{ 4. That's entertainment (cont) } \\
\hline Sub-subtask & 4.2 Like(s) - ing form / Dislike(s) - ing form \\
\hline \multicolumn{1}{|c|}{ Input } & \multicolumn{1}{|c|}{ Action } & \multicolumn{1}{c|}{ Output } \\
\hline 4.2 .1 .1 & 4.2 .1 .1 read & Students have knowledge and \\
principle of & the & understanding in principle of \\
Like(s) - ing & principle of & Like(s) - ing form : Like(s) \\
form & Like(s) - & followed by To + Verb1 or \\
& ing form & Verb - ing \\
\hline
\end{tabular}

Fig. 6. The mapping of the students' learning behavior.

\begin{tabular}{|c|c|c|}
\hline Subtask: & \multicolumn{2}{|c|}{ 4. That's entertainment (cont.) } \\
\hline Sub-subtask: & \multicolumn{2}{|c|}{ 4.2 Like(s) - ing form / Dislike(s) - ing form } \\
\hline Sub-subtask: & \multicolumn{2}{|c|}{$\begin{array}{l}\text { 4.2.1 Like(s) - ing form } \\
\text { 4.2.1.1 principle of Like(s)- ing form }\end{array}$} \\
\hline \multicolumn{2}{|c|}{ Instructional Goal } & $\begin{array}{l}\text { Observable and Measurable } \\
\text { Learning Outcome }\end{array}$ \\
\hline \multicolumn{2}{|c|}{$\begin{array}{l}\text { 4.2.1.1 Give principle of } \\
\text { Like(s) - ing form Learners } \\
\text { can explain principle of } \\
\text { Like(s) - ing form }\end{array}$} & $\begin{array}{l}\text { Learners explain principle of } \\
\text { Like(s) - ing form that Like(s) } \\
\text { followed by To + Verb1 or } \\
\text { Verb-ing }\end{array}$ \\
\hline
\end{tabular}

Fig. 7. Observable and measurable learning outcome.

\begin{tabular}{||l|l||}
\hline \multicolumn{1}{|c|}{ Subtask: 4. That's entertainment (cont) } \\
\hline Sub-sub task: 4.2 Like(s) - ing form / Dislike(s) - ing form \\
4.2.1 Like(s) - ing form
\end{tabular}

Fig. 8. Behavioral objectives and criterion.

\begin{tabular}{|c|c|c|c|c|c|}
\hline \multirow{2}{*}{ Contents } & \multicolumn{4}{|c|}{ Behavior outcome } & \multirow{2}{*}{ Total } \\
\hline & $\mathbf{K}$ & C. & Ap. & A. & \\
\hline \multicolumn{6}{|l|}{$\begin{array}{l}\text { 4.2 Like(s) -ing form/Dislike(s) - } \\
\text { ing form }\end{array}$} \\
\hline \multicolumn{6}{|l|}{ 4.2.1 Like(s) -ing form } \\
\hline $\begin{array}{l}\text { 4.2.1.1 Principle of Like(s) - } \\
\text { ing form }\end{array}$ & - & 1 & - & - & $1^{*}$ \\
\hline \multicolumn{6}{|l|}{$\begin{array}{r}4.2 .1 .2 \text { Examples of senten ces } \\
\text { using Like(s)- ing form }\end{array}$} \\
\hline $\begin{array}{l}\text { 1) Examples of positive } \\
\text { sentences }\end{array}$ & - & 3 & - & - & $3^{* *}$ \\
\hline $\begin{array}{l}\text { 2) Examples of neg ative } \\
\text { sentences }\end{array}$ & - & 3 & - & - & $3^{* *}$ \\
\hline $\begin{array}{l}\text { 3) Examples of question } \\
\text { sentences }\end{array}$ & - & 3 & - & - & $3^{* *}$ \\
\hline Total & - & 10 & - & - & 10 \\
\hline
\end{tabular}

Fig. 9. Table of specifications.
- The classification and level of learning objective: The researchers present the table of test specifications in order to know whether all objectives have been assessed. This step includes the following questions: "How should be evaluate of each objective?", and "what type of test is used for the test design for achieving each objective?" This is shown in Fig. 9.

2) Test design: The steps for test design are as follows:

- Test design must be relative the behavioral learning objectives. The researchers designed varieties of tests which include multiple choices; true-false and matching (see Fig.10).

\begin{tabular}{|c|c|}
\hline \multicolumn{2}{|c|}{$\begin{array}{c}\text { Subtask: } 4 \text {. That's entertainment (cont.) } \\
\text { Sub-sub task: } 4.2 \text { Like(s) - ing form /Dislike(s) - ing form } \\
4.2 .1 \text { Like(s) - ing form }\end{array}$} \\
\hline $\begin{array}{c}\text { Object } \\
\text { (TPO/EO) }\end{array}$ & Cognitive Tests \\
\hline $\begin{array}{l}4.2 .1 .1 \text { Give } \\
\text { principle of } \\
\text { Like(s) - ing } \\
\text { form } \\
\text { Learners } \\
\text { can explain } \\
\text { principle of } \\
\text { Like(s) - ing } \\
\text { form }\end{array}$ & 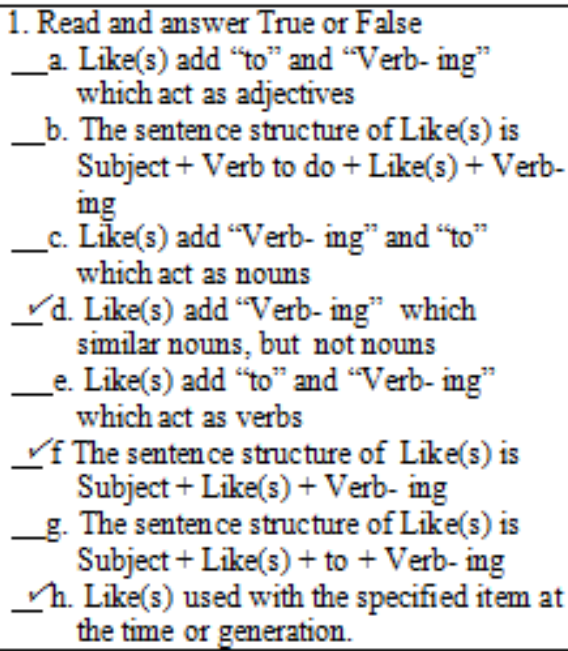 \\
\hline
\end{tabular}

Fig. 10. True-false test design.

- The all tests were evaluated by content experts. These data were then used to compute the index of Item Objective Congruence (IOC). The items in the IOC index that are higher than 0.5 are acceptable.

- After that, the researchers determined the students who studied English for doing the test. Next, the scores of the tests were analyzed for overall quality, reliability, discrimination and difficulty.

- Finally, the researchers select test criteria to be used in pretests, quizzes, and posttests.

\section{RESUlTS AND DiscUSSION}

The result of consider the contents on English subject on cooperative learning with STAD technique on a e-learning with ADDIE model of five content experts are as follows:

1) From the evaluation of the cluster analysis done as part of task inventory, the results showed that the experts accepted it $100 \%$.

2) For the evaluation of relationship between task and task knowledge, the results showed that the experts accepted it $100 \%$.

3) For the evaluation of input/action/output diagram, the results showed that the experts accepted it $100 \%$.

4) For the evaluation of observable and measurable 
learning outcomes, the results showed that the experts accepted it $100 \%$.

5) For the evaluation of learning behavior objectives and criterion, the results showed that the experts accepted it $100 \%$.

6) For the evaluation of the relationship between the learning behavior objectives and the tests, the results showed that the experts accepted it $90 \%$. Some experts recommend that some tests are unclear. The researchers improved the test to achieve good quality.

\section{CONCLUSION AND FURTHER RESEARCH}

The contents design of an e-learning tool for teaching and learning M.5 English subject uses the ADDIE model with the following steps: analysis, design, development, implementation and evaluation. This article is a part of the research on M.5 students' learning outcomes from cooperative learning with STAD technique involving the comparison between normal virtual classroom and virtual classroom with scaffolding. It has presented two models: analysis and design. These two models are directly involved in the design and development of the content However, the remaining steps of the model will be done in following research in the future. The contents and the tests were evaluated by five content experts. The results showed that the experts accepted the designed and development contents. Further this research will development, implementation, and evaluation of e-learning for the English subject.

\section{ACKNOWLEDGMENT}

The researchers would like to thanks the teachers and the experts who participated in this study. In addition, the researchers gratefully acknowledge the support of the Suranaree University of Technology Nakhon Ratchashima, Thailand and Rajamangala University of Technology Isan, Surin Campus, Thailand.

\section{REFERENCES}

[1] R. Kannan. (2009). Difficulties in Learning English as a Second Language. [Online]. Available: http://www.esp-world.info/Articles_26/Original/Difficulties in learning English as a second language.pdf

[2] Bureau of Academic Affairs and Educational Standards, Office of the Basic Education Commission (2551), The Basic Education Core Curriculum B.E. 2551 (A.D. 2008), Bangkok: Agricultural Cooperative of Thailand.

[3] H. Nareenart, "Using films to develop English skills: The use of James Mckernan'S time cycle process of the action research model," Educational Measurement Mahasarakham University, vol. 17, no. 1, pp. 187-199, July 2012.

[4] P. Surai, Teaching English for the Beginner, Bangkok: Srinakharinwirot Prasarnmit University, 1983.

[5] The National Institute of Educational Testing Service. (February 2013). Ordinary National Educational Test of grade 6 academic year 2555 (A.D. 2012). [Online]. Available: http://www.onetresult.niets.or.th/AnnouncementWeb/Notice/FrBasic Stat.aspx

[6] Z. Xu. (2012). Problems and Strategies of Teaching English in Large Classes in the People's Republic of China. [Online]. Available: http://otl.curtin.edu.au/professional_development/conferences/tlf/tlf2 001/xu.html
[7] W. Hiew, "English language teaching and learning issues in Malaysia: Learnings perceptions via face book dialogue journal," Arts, Science \& Commerce, vol. 3, no. 1, pp. 11-19, 2012.

[8] P. Fasawang, "The three-step model: A guideline for teaching English oral communication," Executive Journal, vol. 31, no. 4, pp. 41-45, October-December 2011.

[9] Ministry of education, The Basic Education Core Curriculum B.E. 2544 (A.D. 2001), The Express Transportation Organization of Thailand, 2001.

[10] C. Praphon. (2011). Websites for Teaching English. [Online]. Available: http://www.bpcd.net/new_subject/general/Articles/ 04.pdf.

[11] R. H. Starr, "Cooperative learning in a virtual classroom: Highlights of findings," in Proc. the 1988 ACM Conference on Computer-Supported Cooperative Work, Revision, 1998, pp. 282-290.

[12] E. Chernobilsky, A. Nagarajan, and S. Hmelo, "Problem-based learning online: Multiple perspectives on collaborative knowledge construction," in Proc. the 2005 Conference on Computer Support for Collaborative Learning: Learning 2005: the Next 10 Year! International Society of the Learning Sciences, 2005.

[13] L. T. Thanomporn, Designing e-Learning: Principle of Design and Create Web for Teaching, Bangkok: Arun printing, 2002.

[14] T. C. Reeves, Effective Dimensions of Interactive Learning on the World Wide Web, New Jersey: Educational Technology Publications, 1997.

[15] T. Monchai, "Courseware design and development computer assistant instructional," Major Field in Computer Technology, Department of Technical Education, Graduate College, King Mongkut's Institute of Technology North Bangkok, Bangkok, Thailand, 2002.

[16] B. Seel and Z. Glasgow, Making Instructional Design Decisions, Upper Saddle River, NJ: Merrill, 1998.

[17] E. Lynda, Elevator 2 Student'S Book, Bangkok: Wittaya Academy, 2007.

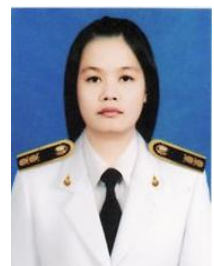

Wiphasith Hiranrat is 32 years old. She was born in Thailand. She graduated with a bachelor's of degree in computer science, Faculty of Information Science from Mahasarakham University (MSU), Thailand in March 2005. She graduated with a diploma in teaching from the Faculty of Education at Sukhothai Thammathirat Open University (STOU), Thailand in November 2004. She graduated with a master's degree in computer technology from the Faculty of Technical Education at King Mongkut's University of Technology North Bangkok (Kmutnb), Thailand in January 2008.

Now she is studying D.I.S. (information technology) School of Information Technology, Suranaree University of Technology, Thailand. Her research interests include e-learning, learning management for disabled children etc.

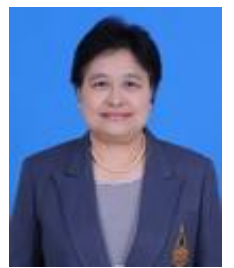

Narumol Ruksasuk is 56 years old. She was born in Thailand. She graduated with a bachelor's of degree in library science, Faculty of Liberal Arts, Thammasat University (TU), Thailand in 1980. She graduated with a master's degree in library science, Faculty of Arts, Chulalongkorn University (CU), Thailand in 1985. And she graduated with Ph.D. in library and information science, School of Information Sciences, University of Pittsburgh, U.S.A. in 2000.

Now she is a lecturer at School of Information Technology, Suranaree University of Technology, Thailand. Her research interests include e-learning, etc.

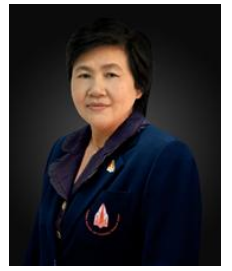

Sumalee Chaijaroen was born in Thailand. She graduated with a bachelor's of degree in education (elementary education), Faculty of Education at Khon Kaen University (KKU), Thailand in 1981 and a bachelor's of degree in education (education technology), Faculty of Education at Khon Kaen University (KKU), Thailand in 1985. She graduated with a master's degree in education technology, Tsukuba University, Japan in 1997. And she graduated with Ph.D. Education technology, Tsukuba University, Japan in 2001.

Now she is a lecturer at Education Technology, Faculty of Education at Khon Kaen University (KKU), Thailand. Her research interests include management of learning, innovation education, education technology, etc. 